\title{
Flavonoids isolated from Citrus platymamma induce mitochondrial-dependent apoptosis in AGS cells by modulation of the PI3K/AKT and MAPK pathways
}

\author{
HO JEONG LEE ${ }^{1 *}$, ARULKUMAR NAGAPPAN ${ }^{2 *}$, HYEON SOO PARK $^{1}$, GYEONG EUN HONG $^{1}$, \\ SILVIA YUMNAM $^{1}$, SUCHISMITA RAHA ${ }^{1}$, VENU VENKATARAME GOWDA SARALAMMA ${ }^{1}$, \\ WON SUP LEE ${ }^{2}$, EUN HEE KIM ${ }^{3}$ and GON SUP KIM ${ }^{1}$
}

\begin{abstract}
${ }^{1}$ Research Institute of Life Science and College of Veterinary Medicine (BK21 Plus Project), Gyeongsang National University, Jinju, Gyeongsang 660-701; ${ }^{2}$ Department of Internal Medicine, Institute of Health Sciences, Gyeongsang National University School of Medicine, Jinju, Gyeongsang 660-702; ${ }^{3}$ Department of Nursing Science, International University of Korea, Jinju, Gyeongsang 660-759, Republic of Korea
\end{abstract}

Received May 6, 2015; Accepted July 3, 2015

DOI: $10.3892 /$ or.2015.4122

\begin{abstract}
Citrus platymamma hort. ex Tanaka (Rutaceae family) has been widely used in Korean folk medicine for its wide range of medicinal benefits including an anticancer effect. In the present study, we aimed to investigate the molecular mechanism of the anticancer effects of flavonoids isolated from Citrus platymamma (FCP) on AGS cells. FCP treatment significantly inhibited AGS cell growth in a dose-dependent manner. Furthermore, FCP significantly increased the percentage of cells in the sub-G1 phase (apoptotic cell population), and apoptosis was confirmed by Annexin V double staining. Chromatin condensation and apoptotic bodies were also noted in the FCP-treated AGS cells. Moreover, immunoblotting results showed that FCP treatment significantly decreased the expression of procaspase- $3,-6,-8$ and -9 , and PARP and increased cleaved caspase- 3 , cleaved PARP and the $\mathrm{Bax} / \mathrm{Bcl}-\mathrm{xL}$ ratio in a dose-dependent manner. In addition, the phosphorylation of AKT was significantly decreased, whereas extracellular signal-related kinase 1/2 (ERK1/2), c-Jun N-terminal kinase (JNK), and p38 mitogen-activated protein kinases (MAPKs) were significantly increased in the FCP-treated AGS cells. Taken together, the cell death of AGS cells in response to FCP was mitochondrial-dependent via modulation of the PI3K/AKT and MAPK pathways. These findings provide new insight for understanding the mechanism
\end{abstract}

Correspondence to: Professor Gon Sup Kim, Research Institute of Life Science and College of Veterinary Medicine, Gyeongsang National University, 900 Gajwadong, Jinju, Gyeongnam 660-701, Republic of Korea

E-mail: gonskim@gnu.ac.kr

*Contributed equally

Key words: Citrus platymamma, flavonoids, AGS cells, apoptosis, PI3K/AKT, p38 MAPK of the anticancer effects of FCP. Thus, FCP may be a potential chemotherapeutic agent for the treatment of gastric cancer.

\section{Introduction}

Gastric cancer is the second most common cancer worldwide next to lung cancer (1), and is a major public health issue in Korea. Currently, the available treatments for gastric cancer are inadequate. With advances in recent techniques, the overall 5-year survival rate of gastric cancer patients ranges from 10 to $30 \%(2,3)$. However, gastric cancer patients in advanced stages have limited treatment options. Hence, there is an urgency to identify novel therapeutic agents that can reduce the mortality of cancer patients with few side effects.

Over the past few years, flavonoids from dietary sources have attracted interest in preventing cancer with low toxicity. Flavonoids are abundantly present in fresh fruits and vegetables and have various health benefits $(4,5)$. Korean Citrus platymamma hort. ex Tanaka (Byungkyul in Korean), a member of the Rutaceae family, has been used in traditional herbal medicines in Korea. It contains abundant flavonoids which have been reported to have various properties that regulate the inflammatory response and halt carcinogenesis and cancer progression (6). It is also speculated that the intake of flavonoids reduces the risk of most types of cancer $(7,8)$. Our previous studies indicated that flavonoids isolated from Korean Citrus aurantium L. effectively inhibited the proliferation of various cancer cells by inducing cell cycle arrest and apoptosis and suppressed inflammatory mediators in L6 skeletal muscle cells (9-12). However, the anticancer effects and the related mechanisms of flavonoids from C. platymamma (FCP) have not yet been elucidated.

Apoptosis is a critical cell death mechanism with a distinctive phenotype and plays an important role in the mechanism of chemotherapies against various types of carcinoma (13). Apoptosis signaling pathways mainly function through two major pathways (the intrinsic pathway - mitochondria-mediated apoptosis and the extrinsic pathway - death receptor-mediated 
apoptosis) $(14,15)$. In addition, anticancer agents activate the $\mathrm{PI} 3 \mathrm{~K} /$ Akt signaling pathway which is critical in regulating cell proliferation and apoptosis (16). In addition, mitogen-activated protein kinases (MAPKs) such as extracellular signal-related kinase 1/2 (ERK1/2), c-Jun N-terminal kinase (JNK), and p38 mitogen-activated protein kinases (p38 MAPKs) are also involved in survival, proliferation and apoptosis (17). Thus, apoptosis plays crucial roles in the anticancer properties of many anticancer molecules by preventing or controlling abnormal cell development (18).

Based on the above evidence, in the present study, we investigated the anticancer activity and the related mechanism of FCP in AGS cells. The present study provides new insight for understanding the mechanism of the anticancer effects of FCP in AGS cells.

\section{Materials and methods}

Isolation offlavonoids from Korean Citrus platymamma Hort. ex Tanaka. The fruit of C. platymamma hort. ex Tanaka was obtained from the Animal Bio-Resources Bank (Jinju, Korea). The flavonoids were isolated, and high-performance liquid chromatography (HPLC) was performed at the Department of Chemistry, Gyeongsang National University by Professor Sung Chul Shin as described previously (19). The FCP samples were stored at $-70^{\circ} \mathrm{C}$ until further use.

Materials and chemicals. RPMI-1640 medium, fetal bovine serum (FBS) and antibiotics (penicillin/streptomycin) were purchased from Gibco (BRL Life Technologies, Grand Island, NY, USA). 3-(4,5-Dimethylthiazol-2-yl)-2,5- diphenyltetrazolium bromide (MTT) was obtained from Sigma-Aldrich (St. Louis, MO, USA). Antibodies to Bcl-xL, Bax, caspase-3, -6, -8 and -9 , cleaved caspase-3, poly(ADP ribose) polymerase (PARP), cleaved PARP, p-Akt, JNK, p-JNK, p38, p-p38, ERK1/2 and p-ERK1/2 were purchased from Cell Signaling Technology (Danvers, MA, USA). The Akt and $\beta$-actin antibodies were obtained from Santa Cruz Biotechnology (Santa Cruz, CA, USA) and Millipore (Billerica, MA, USA), respectively. Horseradish peroxidase (HRP)-coupled goat anti-mouse $\mathrm{IgG}$ and anti-rabbit IgG were purchased from Enzo Life Sciences. Muse ${ }^{\mathrm{TM}}$ Cell Cycle kit and Annexin V and Dead Cell kit were purchased from Millipore. Materials and chemicals used for electrophoresis were obtained from Bio-Rad (Hercules, CA, USA).

Cell culture and viability assay. Human gastric cancer AGS cells were obtained from the Korean Cell Line Bank (Seoul, Korea). The AGS cells were cultured in RPMI-1640 medium supplemented with $10 \%$ (v/v) heat-inactivated FBS and $1 \%$ penicillin/streptomycin in a humidified atmosphere with $5 \%$ $\mathrm{CO}_{2}$ at $37^{\circ} \mathrm{C}$. To assess the effect of FCP on AGS cell growth, the cells were seeded at $10 \times 10^{4}$ cells $/ \mathrm{ml}$ in a 12 -well plate and were treated with FCP at various concentrations $(25,50,75$, $100,125$ and $150 \mu \mathrm{g} / \mathrm{ml})$. After $24 \mathrm{~h}$ of incubation at $37^{\circ} \mathrm{C}$, $100 \mu \mathrm{l}$ of MTT $(0.5 \mathrm{mg} / \mathrm{ml})$ was subsequently added to each well and incubated for $3 \mathrm{~h}$ at $37^{\circ} \mathrm{C}$. The culture medium was then removed, and $500 \mu \mathrm{l}$ of dimethyl sulfoxide (DMSO) was added to each well to dissolve the formazan crystals. After mixing, absorbance was measured at $540 \mathrm{~nm}$ using an enzyme-linked immunosorbent assay (ELISA) plate reader (Bio-Rad).

Cell cycle distribution and analysis of cell apoptosis. The AGS cells were incubated without or with FCP at concentrations of 75 and $150 \mu \mathrm{g} / \mathrm{ml}$ for $24 \mathrm{~h}$ at $37^{\circ} \mathrm{C}$, and the cells were collected, washed with cold PBS, and then centrifuged. The pellet was fixed in cold $70 \%$ ethanol $(\mathrm{v} / \mathrm{v})$ for $3 \mathrm{~h}$ at $-20^{\circ} \mathrm{C}$. The cells were washed once with PBS, and $200 \mu 1$ was transferred to fresh tube. Muse Cell Cycle kit reagent (200 $\mu \mathrm{l})$ was added to each tube and incubation was carried out for $30 \mathrm{~min}$ at room temperature in the dark. For analysis of apoptosis, the pellet was resuspended in $1 \mathrm{ml}$ media and $100 \mu \mathrm{l}$ was transferred to a new tube. Then, $100 \mu \mathrm{l}$ of Muse Annexin V and Dead Cell kit reagent was added to each tube and incubation was carried out for $20 \mathrm{~min}$ at room temperature in the dark. Then, stained samples were analyzed using a Muse ${ }^{\mathrm{TM}}$ Mini FACS machine (Millipore).

Morphological change and DAPI fluorescent staining. The AGS cells were treated with the indicated concentrations of FCP for $24 \mathrm{~h}$ at $37^{\circ} \mathrm{C}$, and the cells were washed with cold PBS and fixed with $37 \%$ formaldehyde (1:4 dilution with $95 \%$ ethanol) for $10 \mathrm{~min}$ at room temperature. The fixed cells were washed with PBS and stained with a 4',6-diamidino-2-phenylindole (DAPI, Vectashield H-1500; Vector Laboratories, Inc., Burlingame, CA, USA). The nuclear morphology of the cells was examined by fluorescence microscopy (x400 magnification; Leica, Germany).

Western blot analysis. For the western blot analysis, the AGS cells were treated with the indicated concentrations of FCP for the indicated times at $37^{\circ} \mathrm{C}$ and the cells were lysed in ice-cold RIPA buffer [1\% (w/w) NP-40, $1 \%$ (w/v) sodium deoxycholate, $0.1 \%$ (w/v) SDS, $0.15 \mathrm{M} \mathrm{NaCl}, 0.01 \mathrm{M}$ sodium phosphate buffer, $\mathrm{pH}$ 7.2, 2 mM EDTA, and $50 \mathrm{mM} \mathrm{NaF}$ (as phosphatase inhibitor) and protease inhibitors]. The protein concentrations were determined using a Bradford assay (Bio-Rad) method (20). Proteins were separated by $12 \%$ SDS-polyacrylamide gel electrophoresis (SDS-PAGE) and transferred to a polyvinyldene fluoride (PVDF) membrane (Immobilon-P, $0.45 \mu \mathrm{m}$; Millipore) using the TE 77 Semi-Dry Transfer Unit (GE Healthcare Life Sciences, Buckinghamshire, UK). The membranes were incubated with the primary antibodies overnight followed by a conjugated secondary antibody to peroxidase. Blots were developed under an ECL detection system (GE Healthcare Life Sciences). The bands were quantitatively analyzed using the Image J program (http://rsb.info.nih.gov).

Statistical analysis. The statistical analysis was calculated by the Student's t-test, using SPSS version 10.0 for Windows (SPSS, Chicago, IL, USA). The results are expressed as the mean \pm standard deviation (SD) of at least three independent experiments. The statistical significance was accepted as $\mathrm{P}<0.05$.

\section{Results}

Quantitative analysis and characterization of FCP. The flavonoids were isolated from the fruit of $C$. platymamma by using HPLC-MS/MS. Totally 13 peaks were identified based on 
Table I. List of identified flavonoids from C. platymamma and the quantification data.

\begin{tabular}{|c|c|c|c|c|c|}
\hline & Compound & $\mathrm{RT}(\min )$ & {$[\mathrm{M}-\mathrm{H}]^{-/} /[\mathrm{M}-\mathrm{H}]^{+}$} & MS/MS & Mean \pm SD \\
\hline 1 & Naringin & 16.93 & $579 /-$ & $459,313,271,193,151$ & $2,483.5 \pm 1.6$ \\
\hline 2 & Hesperidin & 18.45 & $609 /-$ & $608,325,301$ & $1,163.2 \pm 1.6$ \\
\hline 3 & Hydroxypentamethoxyflavone & 39.88 & $/ 389$ & $374,359,341,165$ & $2,785.2 \pm 10.9$ \\
\hline 4 & Hydroxypentamethoxyflavone & 39.88 & 1389 & $374,359,341,165$ & $393.4 \pm 2.3$ \\
\hline 5 & Sinensetin & 42.57 & $-/ 373$ & $\begin{array}{l}373,358,343,339,329,320,312 \\
283,181,151\end{array}$ & $384.7 \pm 4.2$ \\
\hline 6 & Pectolinarigenin & 43.84 & $/ 313$ & $313,285,181,156,153,135$ & $525.8 \pm 13.2$ \\
\hline 7 & Dihydroxytetramethoxyflavone & 44.76 & 375 & $\begin{array}{l}375,360,345,342,314,302,299,285 \\
271,227,212,197,169,166,149\end{array}$ & $370.2 \pm 4.2$ \\
\hline 8 & Nobiletin & 45.32 & $-/ 403$ & $388,373,355,327,211,165$ & $3,911.9 \pm 5.5$ \\
\hline 9 & Heptamethoxyflavone & 46.15 & $/ 433$ & $418,403,385,211,165$ & $674.5 \pm 4.4$ \\
\hline 10 & Tetramethyl-O-isoscutellarein & 47.99 & $-/ 343$ & $\begin{array}{l}343,328,313,299,285,211,181 \\
135,133\end{array}$ & $3,417.4 \pm 11.8$ \\
\hline 11 & Hydroxypentamethoxyflavone & 49.35 & /389 & $374,359,341,165$ & $1,258.3 \pm 7.7$ \\
\hline 12 & Hydroxyhexatamethoxyflavone & 50.56 & $/ 419$ & $\begin{array}{l}404,389,373,361,343,328,315,283, \\
227,165\end{array}$ & $154.5 \pm 3.5$ \\
\hline 13 & Hydroxypentamethoxyflavone & 52.67 & 359 & $\begin{array}{l}359,344,329,311,298,286,241,224, \\
227,211,197,183,179,135\end{array}$ & $258.5 \pm 1.7$ \\
\hline
\end{tabular}

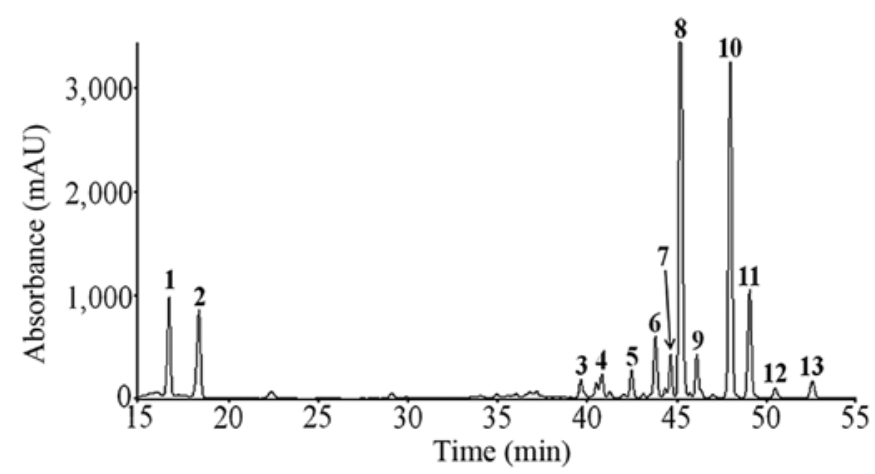

Figure 1. HPLC chromatogram patterns of C. platymamma at $280 \mathrm{~nm}$. The list of identified flavonoids from the peaks included (1) naringin, (2) hesperidin, (3, 4, 11 and 13) hydroxypentamethoxyflavone, (5) sinensetin (6) pectolinarigenin, (7) dihydroxytetramethoxyflavone, (8) nobiletin, (9) heptamethoxyflavone, (10) tetramethyl-O-isoscutellarein, and (12) hydroxyhexatamethoxyflavone. HPLC, high-performance liquid chromatography.

the HPLC retention time and the ultraviolet-visible spectra of standard compounds in a library (Fig. 1). The flavonoids were identified according to the peaks of the HPLC chromatogram and the mass-spectral and quantification data are provided in Table I.

FCP inhibits the growth of AGS cells. To determine the appropriate inhibitory concentrations of FCP, firstly AGS cells were treated with various concentrations $(0-150 \mu \mathrm{g} / \mathrm{ml})$ for $24 \mathrm{~h}$ and cell viability was evaluated by MTT assay. As shown in Fig. 2A, FCP showed a dose-dependent inhibitory effect at $24 \mathrm{~h}$ when compared to the control (DMSO only), and the $50 \%$ inhibitory concentration $\left(\mathrm{IC}_{50}\right)$ value was $\sim 150 \mu \mathrm{g} / \mathrm{ml}$ $(\mathrm{P}<0.01$ for the FCP-treated group compared with the control).
Hence, we used FCP at concentrations of 0,75 and $150 \mu \mathrm{g} / \mathrm{ml}$ for the subsequent experiments. Microscopic examination revealed changes in cell shape, such as cell shrinkage and a decrease in cell numbers was also observed in the FCP-treated cells (Fig. 2B).

FCP induces apoptosis in AGS cells. Next, flow cytometry was performed to determine cell cycle distribution and the population of cell death in the FCP-treated AGS cells. FCP treatment increased the percentage of the sub-G1 cells (apoptotic cell population) by $18,41(\mathrm{P}<0.01)$ and $45 \%(\mathrm{P}<0.01)$ at 0 , 75 and $150 \mu \mathrm{g} / \mathrm{ml}$, respectively. Meanwhile, FCP substantially decreased the G0/G1, S and G2/M populations (Fig. 3). We also assessed the effect of FCP on the induction of apoptosis in AGS cells by Annexin V-FITC/PI double-labeled staining and flow cytometry. As shown in Fig. 4A and B, FCP significantly increased the early apoptotic cell proportion and the late apoptotic cell proportion of AGS cells in a dose-dependent manner. Moreover, apoptotic changes such as nuclear fragmentation and apoptotic bodies were also observed in the FCP-treated AGS cells at 75 and $150 \mu \mathrm{g} / \mathrm{ml}$ by Hoechest 33342 staining (Fig. 4C). These results suggest that FCP could induce cell death in the AGS cells.

FCP induce caspase activation and subsequent cleavage of PARP in AGS cells. Western blotting was performed to determine whether FCP-induced cell death was caspase-dependent. In addition, we examined the expression of apoptosis-related proteins, such as Bax and Bcl-2, in the FCP-treated AGS cells. The results showed that the expression of procaspase- $3,-6,-8$ and -9 was significantly decreased while cleaved caspase- 3 and cleaved PARP were significantly increased in a dose-dependent manner (Fig. 5). No significant changes were found in PARP expression. FCP also increased the $\mathrm{Bax} / \mathrm{Bcl}-\mathrm{xL}$ ratio in the 


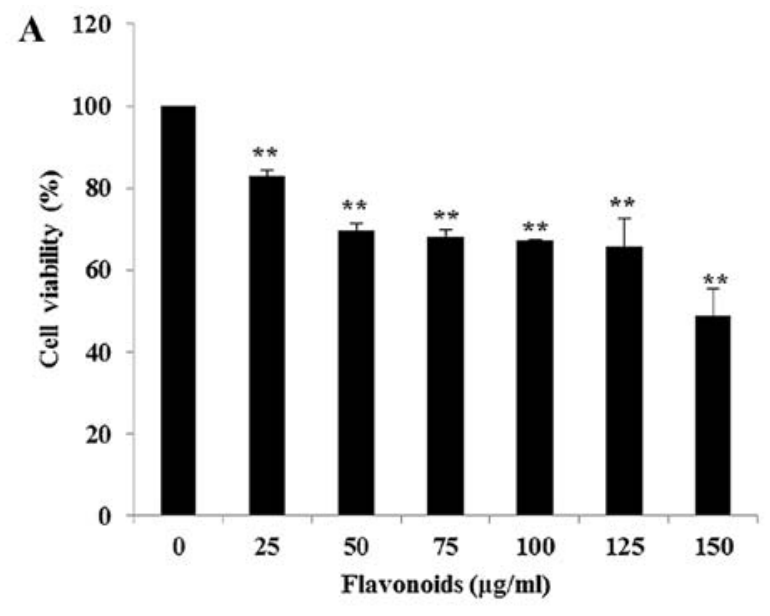

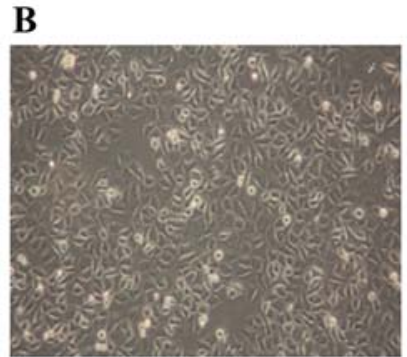

$0 \mu \mathrm{g} / \mathrm{ml}$

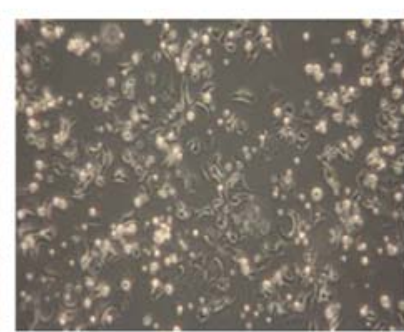

$75 \mu \mathrm{g} / \mathrm{ml}$

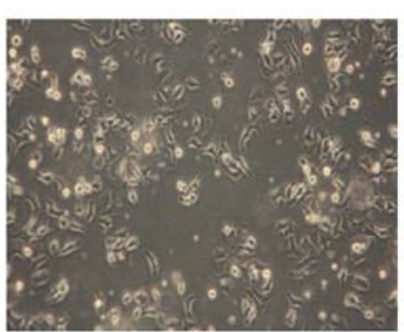

$150 \mu \mathrm{g} / \mathrm{ml}$

Figure 2. Inhibitory effects of FCP on AGS cells. The AGS cells were treated with the indicated concentrations of FCP for 24 h. (A) Cell viability was determined by an MTT assay. The data are expressed as the mean \pm standard deviation (SD) of at least three independent experiments $\left({ }^{*} \mathrm{P}<0.05\right.$, ${ }^{* * *} \mathrm{P}<0.01$ compared to the control). (B) Morphology of the cells was examined under light microscopy (x400 magnification).

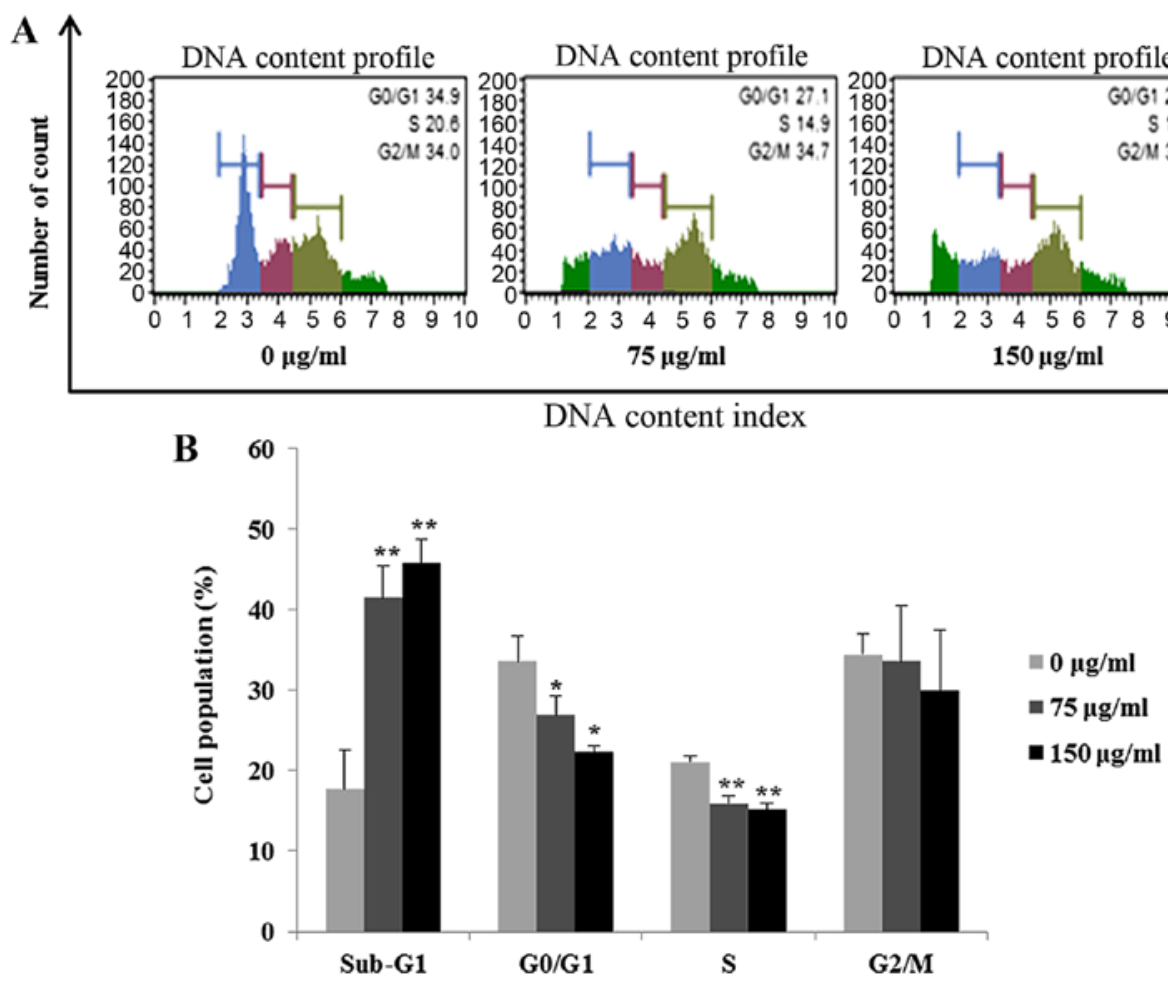

Figure 3. Regulatory effect of FCP on cell cycle progression of AGS cells. The AGS cells were treated with the indicated concentrations of FCP for $24 \mathrm{~h}$. (A and B) Cell cycle distribution was determined by using the Muse Cell Cycle kit, and stained samples were analyzed with the Muse ${ }^{\mathrm{TM}}$ Mini FACS machine The data are expressed as the mean \pm standard deviation $(\mathrm{SD})$ of at least three independent experiments $\left({ }^{*} \mathrm{P}<0.05,{ }^{* * *} \mathrm{P}<0.01\right.$ compared to the control).

AGS cells in a dose-dependent manner. These results suggest that FCP induced caspase-dependent apoptosis in AGS cells.
FCP modulates the PI3K/AKT and MAPK pathways in the AGS cells. The PI3K/AKT and MAPK signaling pathways 
A

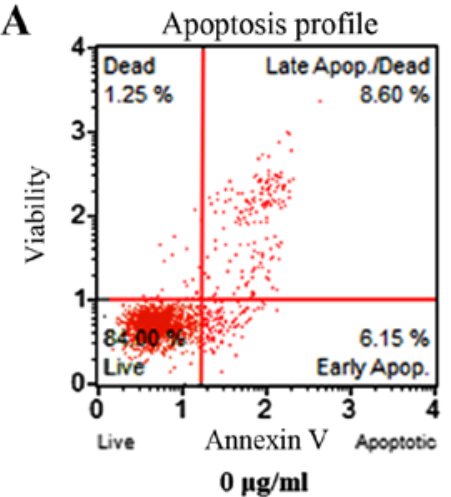

B
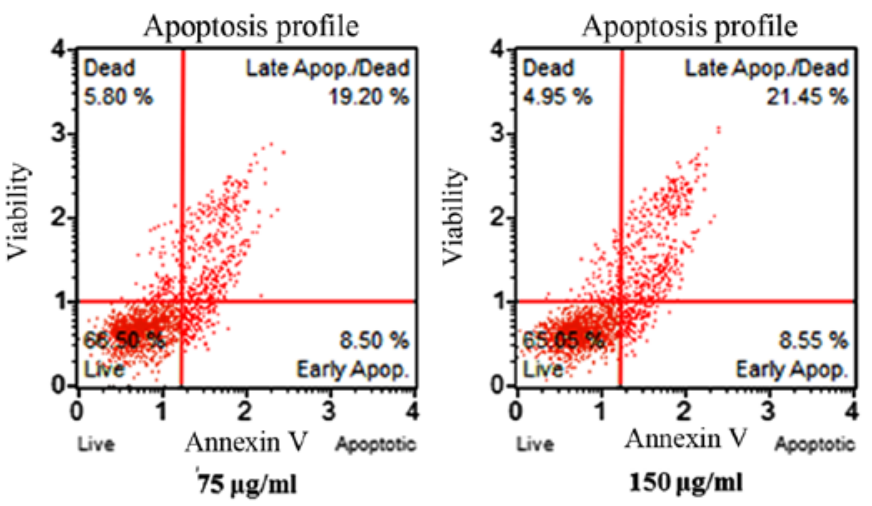

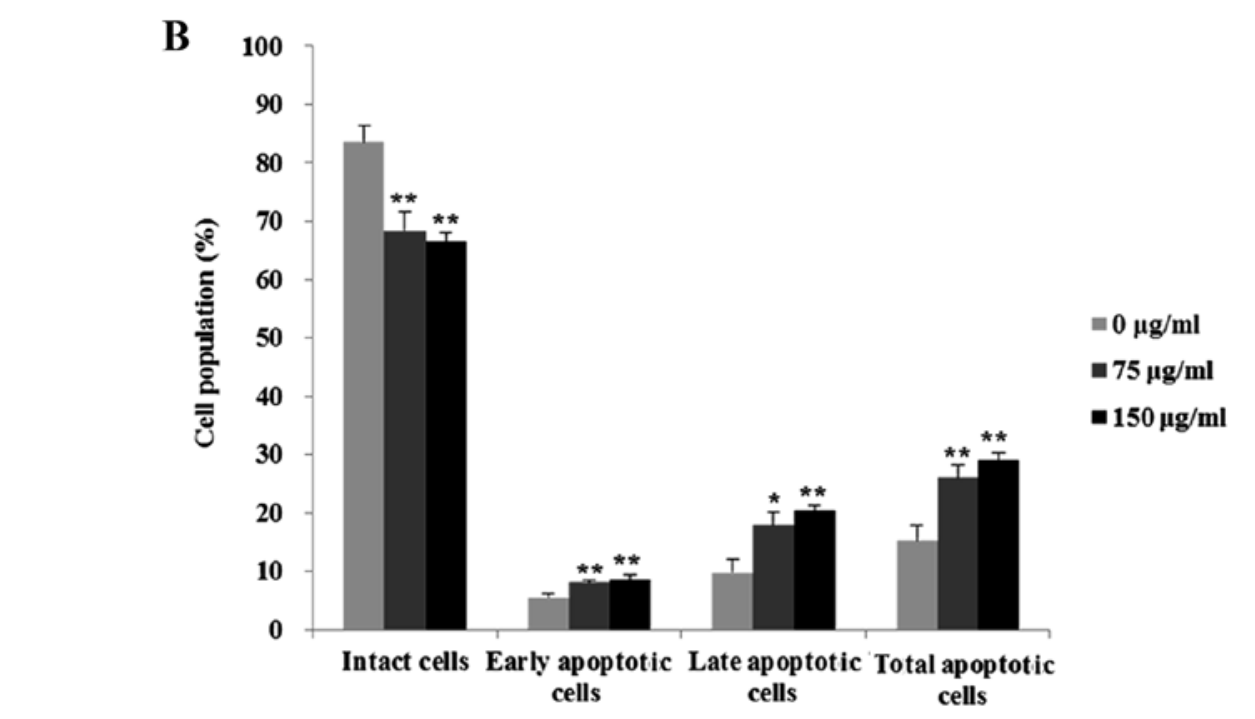

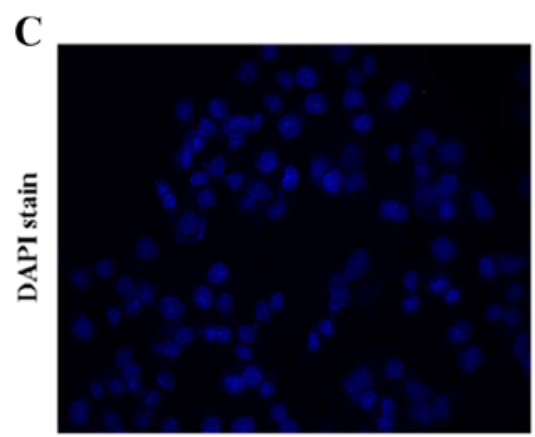

$0 \mu \mathrm{g} / \mathrm{ml}$

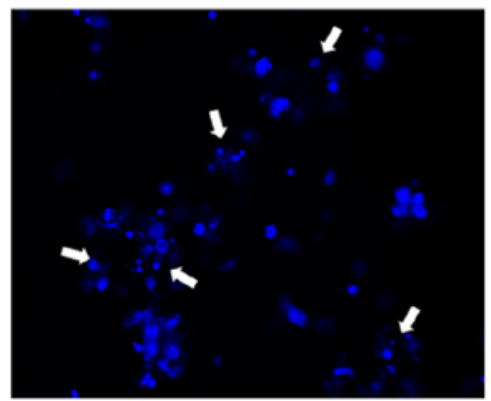

$75 \mu \mathrm{g} / \mathrm{ml}$

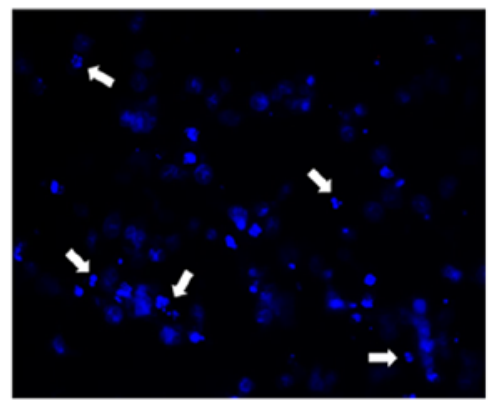

$150 \mu \mathrm{g} / \mathrm{ml}$

Figure 4. Regulatory effect of FCP on the apoptosis of AGS cells. The AGS cells were treated with the indicated concentrations of FCP for $24 \mathrm{~h}$ (A and B) Apoptosis was assessed by Annexin V-PI double staining using the Muse ${ }^{\mathrm{TM}}$ Mini FACS machine. The data are expressed as the mean \pm standard deviation (SD) of at least three independent experiments $\left({ }^{*} \mathrm{P}<0.05,{ }^{* *} \mathrm{P}<0.01\right.$ compared to the control). (C) The cells were stained with DAPI and analyzed by fluorescence microscopy (white arrows indicate fragmented or condensed nuclei).

play an important role in regulating cell proliferation and apoptosis. Since the activity of AKT is regulated by phosphorylation, we examined the phosphorylation status of PI3K/AKT and MAPKs by immunoblotting during the FCP-induced apoptosis in AGS cells. FCP significantly dephosphorylated AKT at 75 and $150 \mu \mathrm{g} / \mathrm{ml}$ but no effects were found in total AKT (Fig. 6). Moreover, the phosphorylated forms of ERK1/2, JNK and p38 MAPK were significantly increased at 75 and $150 \mu \mathrm{g} / \mathrm{ml}$, but no effects were found on total ERK1/2, JNK and p38 MAPK (Fig. 6). These findings suggest that FCP induced the apoptosis in AGS cells by modulating the PI3K/ AKT and MAPK pathways.

\section{Discussion}

The present study was designed to determine whether FCP induces cell death and to further investigate the underlying mechanisms of the FCP-induced apoptosis of AGS cells. Flavonoids are naturally occurring botanical polyphenols present in plant foods and can safely modulate the physiological function and enhance the anticancer activity against various human cancer cell lines (21). Furthermore, the pharmacological activities of FCP against inflammation, allergies, viruses, cancer, and other ailments have been reported (22). In addition, flavonoids and polyphenols from various herbal plants such as 


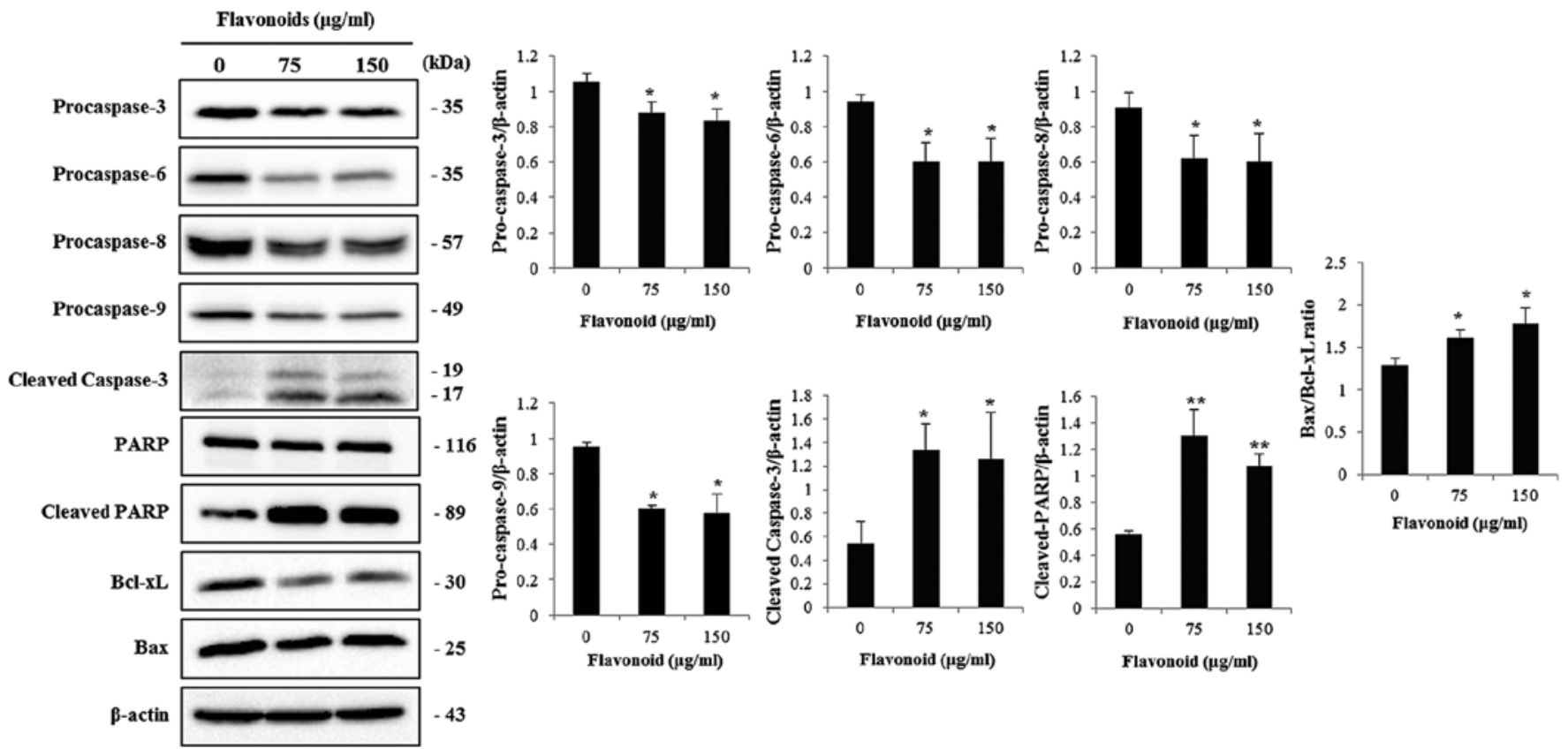

Figure 5. Caspase activation and subsequent cleavage of PARP in the FCP-treated AGS cells. The AGS cells were treated with the indicated concentrations of FCP for $24 \mathrm{~h}$. The cell lysates were subjected to SDS-PAGE and analyzed by immunoblotting. Densitometric analyses of procaspase-3, $-6,-8$, and -9 , cleaved caspase-3, PARP and cleaved PARP and the Bax/Bcl-xL ratio are expressed as mean \pm SD of three independent experiments $\left({ }^{*} \mathrm{P}<0.05\right.$, ${ }^{* *} \mathrm{P}<0.01$ compared with the control).
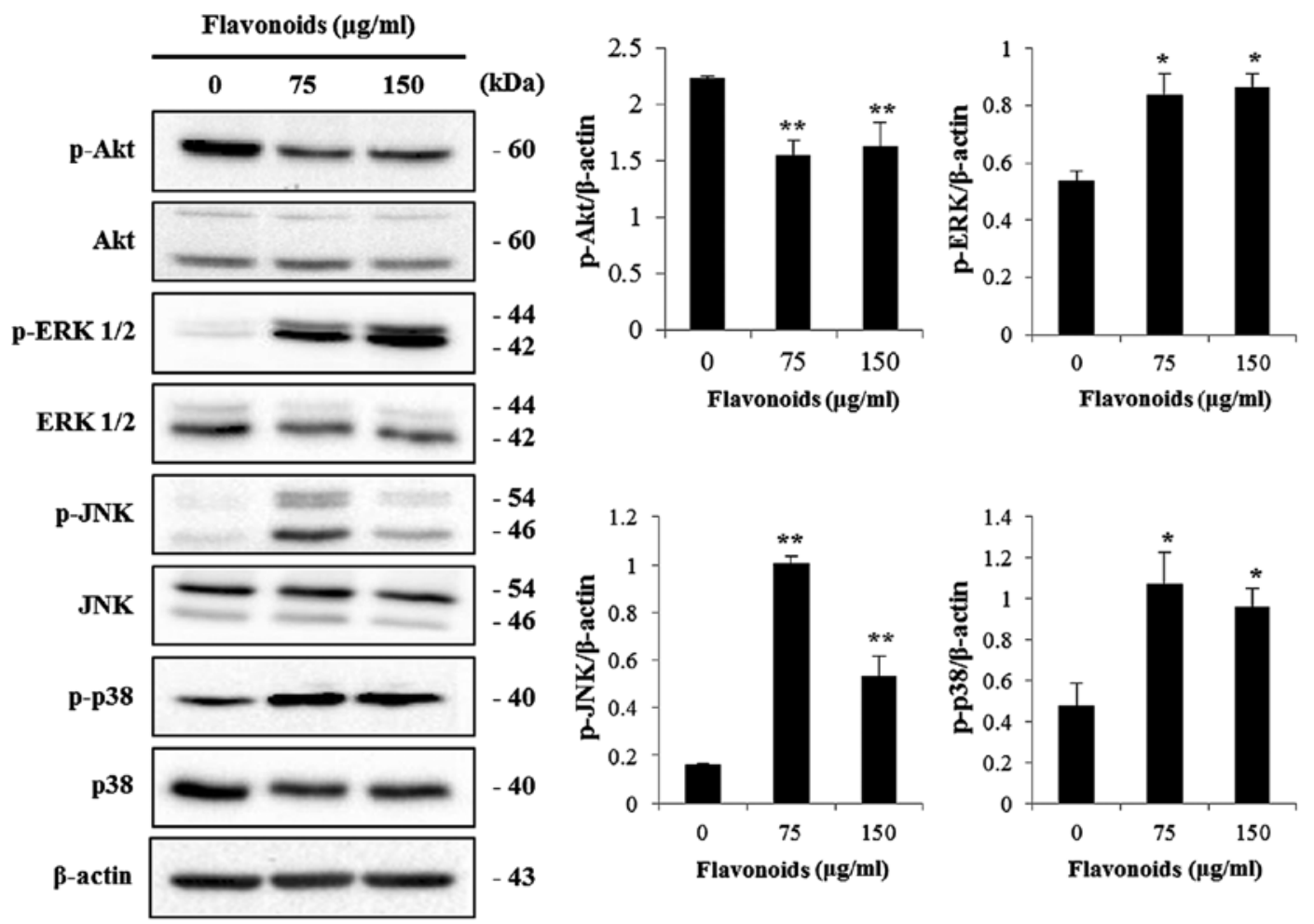

Figure 6. FCP modulates the PI3K/AKT and MAPK signaling pathways in the AGS cells. The AGS cells were treated with the indicated concentrations of FCP for $24 \mathrm{~h}$. The cell lysates were subjected to SDS-PAGE and analyzed by immunoblotting. Densitometric analyses of AKT, p-AKT, ERK1/2, p-ERK1/2, JNK, p-JNK, p38, and p-p38 MAPK are expressed as mean \pm SD of three independent experiments $\left({ }^{*} \mathrm{P}<0.05,{ }^{* * *} \mathrm{P}<0.01\right.$ compared with the control).

Scutellaria baicalensis G., Lonicera japonica T. exhibit antiinflammatory and anticancer activities by inducing cell cycle arrest and apoptosis in various cancer cell lines $(23,24)$. In addition, monomers such as naringin, nobiletin and hesperetin exhibit anticancer effects by cell cycle arrest and the apoptosis pathway in human cancer cell lines $(25,26)$. In the present study, we investigated the anticancer activity of FCP on AGS human gastric cancer cells. 


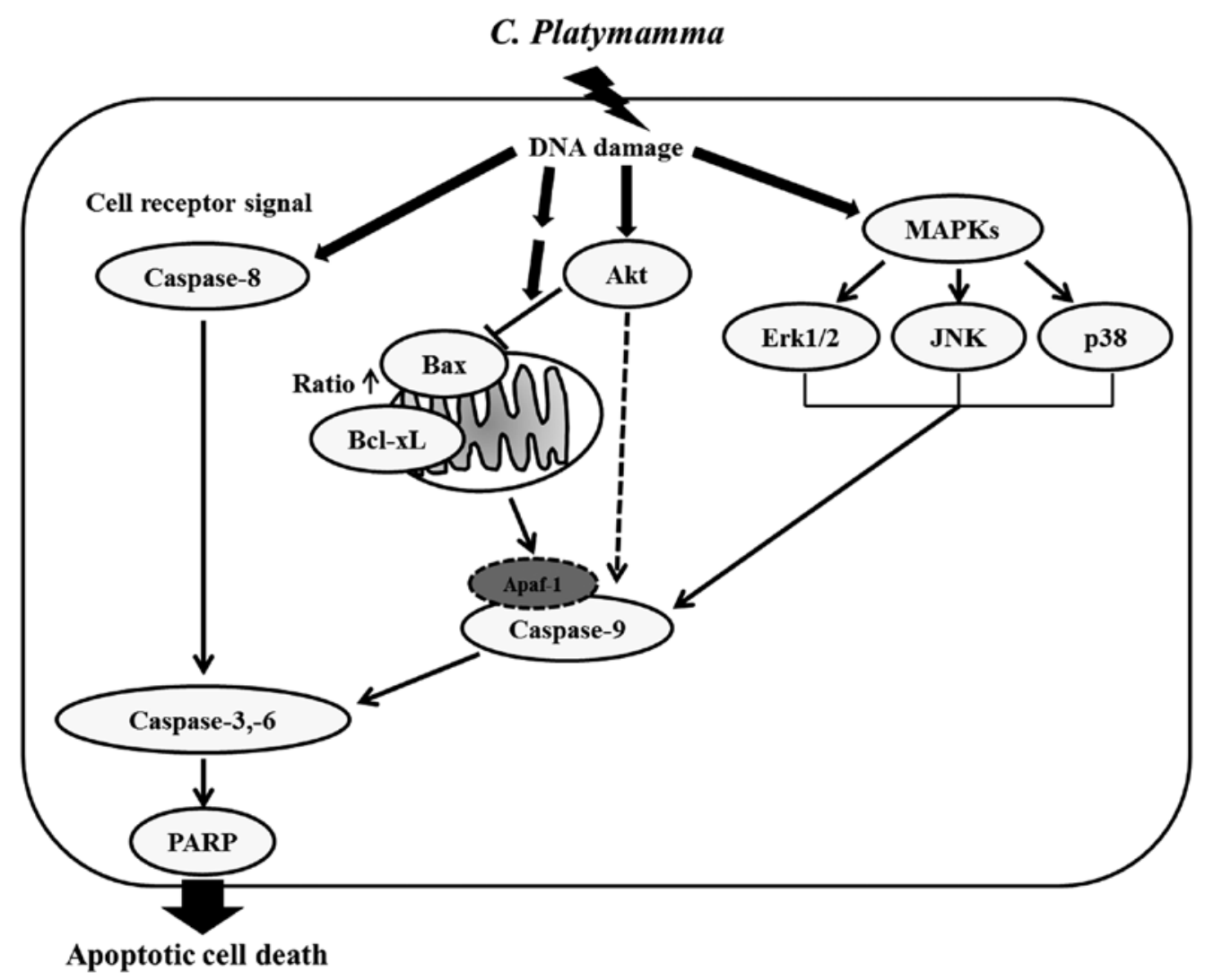

Figure 7. Schematic diagram representing the anticancer mechanism of the FCP-induced apoptosis in AGS cells. FCP induced mitochondrial-dependent apoptosis by upregulation of the Bax/Bcl-xL ratio, caspase-3 activation and subsequent cleavage of PARP. Furthermore, FCP activates PI3K/AKT and MAPK signaling pathways in AGS cells. Taken together, the PI3K/AKT and MAPK pathways are involved in FCP-induced apoptosis in AGS cells, and FCP may have chemotherapeutic potential for the treatment of gastric cancer ( $\rightarrow$ indicates activation, $\perp$ indicates inhibition, --- indicates indirect or multiple pathways).

Firstly, FCP significantly suppressed the growth of AGS cells in a dose-dependent manner. Evidence suggests that apoptosis (type I programmed cell death) is the most popular underlying mechanism by which various anticancer and chemopreventive agents including natural compounds exert anticancer effects (27). Previous studies have demonstrated that the mechanism of cell apoptosis is through the caspase signaling pathway. Recently, our studies demonstrated that cell cycle aberrations often lead to apoptosis in various cancer cell lines $(11,12)$. Presently, accumulation of sub-G1 phase cells (indication of apoptosis) was found in the FCP-treated AGS cells in a dose-dependent manner (Fig. 3). Furthermore, apoptosis was confirmed by FITC-Annexin V and PI double staining (Fig. 4A and B). Similar results have been reported on the induction of apoptosis in various cancer cell lines $(11,12,28)$. In addition, cleaved nuclei and apoptotic bodies were found in the FCP-treated cells (Fig. 4C). These results revealed that FCP effectively suppressed the growth of AGS cells and induced apoptosis.

For the evaluation of their underlying mechanisms, immunoblotting was performed. The results showed that the expression of procaspase $-3,-6,-8$ and -9 was significantly downregulated in a dose-dependent manner. Caspase-3 is a crucial executioner caspase that activates cleavage of PARP which results in apoptosis. In our study, the increased expression of cleaved caspase-3 simultaneously induced PARP cleavage (Fig. 5). These results indicate that FCP induce apoptosis in a caspase3-dependent manner. Moreover, the Bcl-2 family plays an important role in apoptosis and are apoptotic regulatory proteins which control the mitochondrial apoptotic process. The pro-apoptotic and anti-apoptotic proteins of the Bcl-2 family in the cell, determines whether a cell lives or dies (29). Bcl-xL interacts with the mitochondrial plasma membrane and protects from other apoptotic factors, such as Bax and Bak that prevents induced cytochrome $c$ from the plasma membrane. A previous study demonstrated that nobiletin induces apoptosis in various tumor cell lines via inhibition of overexpression of the $\mathrm{Bcl}$ family of proteins (26). The ratio of Bax/Bcl-xL appears to be a determining factor of apoptosis. In the present study, $\mathrm{Bcl}-\mathrm{xL}$ was significantly downregulated, whereas Bax protein was unchanged while the ratio of $\mathrm{Bax} / \mathrm{Bcl}-\mathrm{xL}$ was upregulated in the FCP-treated AGS cells (Fig. 5). Cytochrome $c$ can bind to APAF-1 when it is released from the mitochondria into the cytosol by increasing the $\mathrm{Bax} / \mathrm{Bcl}-\mathrm{xL}$ ratio, thus leading to the activation of caspase- 3 and finally apoptosis.

We further examined the phosphorylation status of PI3K/AKT and MAPKs by immunoblotting to elucidate the molecular mechanism and pathways involved in FCP-induced apoptosis. We demonstrated that FCP inhibited the constitutive level of PI3K and its downstream target AKT (Fig. 6), which have been reported to regulate cell proliferation and apoptosis. Similarly to our results, the inhibition of the PI3K/Akt signaling pathway can induce the apoptosis of various types of cancer cells $(30,31)$. Moreover, the MAPK signaling pathway is also involved in survival, proliferation and apoptosis and consists of three major groups: ERKs, JNKs and the p38 MAPKs (32). Even though activation of the ERK1/2 pathway is generally 
associated with cell proliferation and survival, it has also been reported to stimulate apoptosis in $\mathrm{T}$ cells through Fas ligand expression (33). In addition, ERK1/2 induces apoptosis via prevention of the inactivation of a member of the pro-apoptotic Bcl-2 family, BAD (34). Moreover, JNK is a downstream kinase of the MAPK family which has been reported to regulate the expression of receptors such as Fas and the Fas ligand in apoptosis (35). JNK is also involved in the intrinsic apoptosis pathway where activated JNK modulates the expression of pro-apoptotic proteins such as Bid and Bax and stimulates the release of cytochrome $c$ from mitochondria into the cytosol (36). Activated JNK also downregulates the expression of Bcl-2, an anti-apoptotic protein (37). It has also been demonstrated that activated p38 MAPK stimulates apoptosis in various cell lines in response to a variety of stimuli (38). Similar expression patterns were observed in our experiments. Phosphorylated forms of ERK1/2, JNK and p38 MAPK were increased in the FCP-treated AGS cells (Fig. 6). These results revealed that PI3K/AKT and MAPKs are involved in the apoptosis induced by FCP in AGS cells.

In conclusion, we demonstrated that FCP suppressed cell viability and induced caspase-dependent cell death in the AGS cells. The induction of apoptosis triggered in the FCP-treated AGS cells was modulated by the PI3K/AKT and MAPK signaling pathways (Fig. 7). To our knowledge, this is the first study to elucidate the anticancer properties of FCP in AGS cells. Thus, FCP may be a potential chemotherapeutic agent for the treatment of human gastric cancer.

\section{Acknowledgements}

The present study was supported by a grant from the National Research Foundation (NRF) of Korea funded by the Ministry of Science, ICT and Future Planning (nos. 2012M3A9B8019303 and 2012R1A2A2A06045015) and the National R\&D Program for Cancer Control, Ministry for Health, Welfare and Family Affairs, Republic of Korea (no. 0820050).

\section{References}

1. Crew KD and Neugut AI: Epidemiology of gastric cancer. World J Gastroenterol 12: 354-362, 2006.

2. Green D, Ponce de Leon S,Leon-Rodriguez Eand Sosa-SanchezR: Adenocarcinoma of the stomach: Univariate and multivariate analysis of factors associated with survival. Am J Clin Oncol 25: 84-89, 2002.

3. Harrison LE, Karpeh MS and Brennan MF: Extended lymphadenectomy is associated with a survival benefit for node-negative gastric cancer. J Gastrointest Surg 2: 126-131, 1998.

4. Moufida S and Marzouk B: Biochemical characterization of blood orange, sweet orange, lemon, bergamot and bitter orange. Phytochemistry 62: 1283-1289, 2003.

5. Acunzo J, Katsogiannou M and Rocchi P: Small heat shock proteins HSP27 (HspB1), $\alpha \mathrm{B}$-crystallin (HspB5) and HSP22 (HspB8) as regulators of cell death. Int J Biochem Cell Biol 44: 1622-1631, 2012

6. Havsteen B: Flavonoids, a class of natural products of high pharmacological potency. Biochem Pharmacol 32: 1141-1148, 1983.

7. Rossi M, Garavello W, Talamini R, La Vecchia C, Franceschi S, Lagiou P, Zambon P, Dal Maso L, Bosetti C and Negri SE: Flavonoids and risk of squamous cell esophageal cancer. Int J Cancer 120: 1560-1564, 2007.

8. Theodoratou E, Kyle J, Cetnarskyj R, Farrington SM, Tenesa A, Barnetson R, Porteous M, Dunlop M and Campbell H: Dietary flavonoids and the risk of colorectal cancer. Cancer Epidemiol Biomarkers Prev 16: 684-693, 2007.
9. Alaiya AA, Franzén B, Auer G and Linder S: Cancer proteomics: From identification of novel markers to creation of artifical learning models for tumor classification. Electrophoresis 21: 1210-1217, 2000

10. Kim JA, Park HS, Kang SR, Park KI, Lee DH, Nagappan A, Shin SC, Lee WS, Kim EH and Kim GS: Suppressive effect of flavonoids from Korean Citrus aurantium L. on the expression of inflammatory mediators in L6 skeletal muscle cells. Phytother Res 26: 1904-1912, 2012.

11. Park KI, Park HS, Nagappan A, Hong GE, Lee H, Kang SR, Kim JA, Zhang J, Kim EH, Lee WS, et al: Induction of the cell cycle arrest and apoptosis by flavonoids isolated from Korean Citrus aurantium L. in non-small-cell lung cancer cells. Food Chem 135: 2728-2735, 2012.

12. Lee DH, Park KI, Park HS, Kang SR, Nagappan A, Kim JA, Kim EH, Lee WS, Hah YS, Chung HJ, et al: Flavonoids isolated from Korea Citrus aurantium L. induce G2/M phase arrest and apoptosis in human gastric cancer AGS cells. Evid Based Complement Alternat Med 2012: 515901, 2012.

13. Han SI, Kim YS and Kim TH: Role of apoptotic and necrotic cell death under physiologic conditions. BMB Rep 41: 1-10, 2008.

14. Reed JC, Miyashita T, Takayama S, Wang HG, Sato T, Krajewski S, Aimé-Sempé C, Bodrug S, Kitada S and Hanada M: BCL-2 family proteins: Regulators of cell death involved in the pathogenesis of cancer and resistance to therapy. J Cell Biochem 60: 23-32, 1996.

15. Stennicke HR and Salvesen GS: Properties of the caspases. Biochim Biophys Acta 1387: 17-31, 1998.

16. Kennedy SG, Wagner AJ, Conzen SD, Jordán J, Bellacosa A, Tsichlis PN and Hay N: The PI 3-kinase/Akt signaling pathway delivers an anti-apoptotic signal. Genes Dev 11: 701-713, 1997.

17. Widmann C, Gibson S, Jarpe MB and Johnson GL: Mitogen-activated protein kinase: Conservation of a three-kinase module from yeast to human. Physiol Rev 79: 143-180, 1999.

18. Hengartner MO: The biochemistry of apoptosis. Nature 407: 770-776, 2000.

19. Lee DH, Lee TH, Jung $\mathrm{CH}$ and Kim YH: Wogonin induces apoptosis by activating the AMPK and $\mathrm{p} 53$ signaling pathways in human glioblastoma cells. Cell Signal 24: 2216-2225, 2012.

20. Bradford MM: A rapid and sensitive method for the quantitation of microgram quantities of protein utilizing the principle of protein-dye binding. Anal Biochem 72: 248-254, 1976.

21. Middleton E Jr, Kandaswami C and Theoharides TC: The effects of plant flavonoids on mammalian cells: Implications for inflammation, heart disease, and cancer. Pharmacol Rev 52: 673-751, 2000.

22. Oh YC, Cho WK, Oh JH, Im GY, Jeong YH, Yang MC and Ma JY: Fermentation by Lactobacillus enhances anti-inflammatory effect of Oyaksungisan on LPS-stimulated RAW 264.7 mouse macrophage cells. BMC Complement Altern Med 12: 17, 2012.

23. Hong GE, Kim JA, Nagappan A, Yumnam S, Lee HJ, Kim EH, Lee WS, Shin SC, Park HS and Kim GS: Flavonoids identified from Korean Scutellaria baicalensis Georgi inhibit inflammatory signaling by suppressing activation of NF- $\kappa \mathrm{B}$ and MAPK in RAW 264.7 cells. Evid Based Complement Alternat Med 2013: 912031, 2013.

24. Park HS, Park KI, Lee DH, Kang SR, Nagappan A, Kim JA, Kim EH, Lee WS, Shin SC, Hah YS, et al: Polyphenolic extract isolated from Korean Lonicera japonica Thunb. induce G2/M cell cycle arrest and apoptosis in HepG2 cells: Involvements of PI3K/Akt and MAPKs. Food Chem Toxicol 50: 2407-2416, 2012.

25. Kim DI, Lee SJ, Lee SB, Park K, Kim WJ and Moon SK: Requirement for Ras/Raf/ERK pathway in naringin-induced G1-cell-cycle arrest via p21WAF1 expression. Carcinogenesis 29: 1701-1709, 2008.

26. Luo G, Guan X and Zhou L: Apoptotic effect of citrus fruit extract nobiletin on lung cancer cell line A549 in vitro and in vivo. Cancer Biol Ther 7: 966-973, 2008.

27. Shi Y: Caspase activation: Revisiting the induced proximity model. Cell 117: 855-858, 2004.

28. Nagappan A, Park KI, Park HS, Kim JA, Hong GE, Kang SR, Lee H, Kim EH, Lee WS, Won CK, et al: Vitamin C induces apoptosis in AGS cells by down-regulation of 14-3-3 $\sigma$ via a mitochondrial dependent pathway. Food Chem 135: 1920-1928, 2012.

29. Wong WW and Puthalakath $\mathrm{H}$ : Bcl-2 family proteins: The sentinels of the mitochondrial apoptosis pathway. IUBMB Life 60: 390-397, 2008.

30. Hussain AR, Al-Rasheed M, Manogaran PS, Al-Hussein KA, Platanias LC, Al Kuraya K and Uddin S: Curcumin induces apoptosis via inhibition of PI3'-kinase/AKT pathway in acute T cell leukemias. Apoptosis 11: 245-254, 2006. 
31. Gururajan M, Dasu T, Shahidain S, Jennings CD, Robertson DA, Rangnekar VM and Bondada S: Spleen tyrosine kinase (Syk), a novel target of curcumin, is required for B lymphoma growth. J Immunol 178: 111-121, 2007.

32. Raman M, Chen W and Cobb MH: Differential regulation and properties of MAPKs. Oncogene 26: 3100-3112, 2007.

33. van den Brink MR, Kapeller R, Pratt JC, Chang JH and Burakoff SJ: The extracellular signal-regulated kinase pathway is required for activation-induced cell death of T cells. $\mathrm{J}$ Biol Chem 274: 11178-11185, 1999.

34. Basu S, Bayoumy S, Zhang Y, Lozano J and Kolesnick R: BAD enables ceramide to signal apoptosis via Ras and Raf-1. J Biol Chem 273: 30419-30426, 1998.
35. Faris M, Kokot N, Latinis K, Kasibhatla S, Green DR, Koretzky GA and Nel A: The c-Jun N-terminal kinase cascade plays a role in stress-induced apoptosis in Jurkat cells by up-regulating Fas ligand expression. J Immunol 160: 134-144, 1998.

36. Dhanasekaran DN and Reddy EP: JNK signaling in apoptosis. Oncogene 27: 6245-6251, 2008.

37. Sinha K, Das J, Pal PB and Sil PC: Oxidative stress: The mitochondria-dependent and mitochondria-independent pathways of apoptosis. Arch Toxicol 87: 1157-1180, 2013.

38. Kang YJ, Zhou ZX, Wang GW, Buridi A and Klein JB: Suppression by metallothionein of doxorubicin-induced cardiomyocyte apoptosis through inhibition of p38 mitogen-activated protein kinases. J Biol Chem 275: 13690-13698, 2000. 